\title{
Os Relatórios do Desenvolvimento Humano e a insegurança humana proveniente da crise da água e das mudanças climáticas
}

\author{
Maria José de Rezende \\ Universidade Estadual de Londrina, Londrina, Brasil. \\ Email: mjderezende@gmail.com
}

\begin{abstract}
Resumo: Através de uma pesquisa documental histórico-hermenêutica tentar-se-á sistematizar não só o que os formuladores dos RDHs comprendem por insegurança humana vinculada à crise da água (RDH de 2006), às mudanças climáticas (RDH de 2007/2008) e ao desenvolvimento insustentável, mas também como eles tentam levar aos governantes, lideranças políticas, organizações da sociedade civil, entre outros agentes, uma proposta de construção de ações e de procedimentos pautados na necessidade de vencer a insegurança humana na qual estão mergulhados todos os indivíduos mais pobres e, portanto, desprovidos de rendimento (que seja capaz de garantir o suprimento das necessidades básicas) e de acesso à educação, à saúde, ao saneamento, à água potável, à moradia, a oportunidades de emprego, a terras férteis, à participação política e à liberdade de modo geral.

Palavras-Chaves: Desenvolvimento e segurança humanos, aspectos multidimensionais,Nações Unidas.
\end{abstract}

\section{Los Informes del Desarrollo Humano y la inseguridad humana proveniente de la crisis del agua y de los cambios climáticos}

Resumen: A través de una investigación documental histórica- hermenéutica, se ha intentado sistematizar, no solo lo que los formuladores de los RDHs entienden por inseguridad humana vinculada a la crisis del agua (RDH de 2006), a los cambios climáticos (RDH de 2007/2008) y al desarrollo insostenible, mas también, como ellos intentan llevar a los gobernantes, líderes políticos, organizaciones de la sociedad civil, entre otros agentes, una propuesta de construcción de acciones y procedimientos pautados en la necesidad de vencer la inseguridad humana en la cual están sumergidos todos los individuos más pobres, y por lo tanto, desprovistos de renta (que sea capaz de garantizar la provisión de las necesidades básicas) y el acceso a la educación, a la salud, al saneamiento, al agua potable, a la habitación, a oportunidades de empleo, a tierras fértiles, a la participación política y, de modo general, a la libertad.

Palabras Clave: Desarrollo y seguridad humana, aspectos multidimensionales, Naciones Unidas. 


\title{
Human Development Reports published between 2006 and 2008 and human insecurity from the water crisis and climate change
}

\begin{abstract}
Through a historical-hermeneutic documentary research we will try to systematize not only what the HDRs understand by human insecurity linked to water crisis (HDR 2006), climate change (HDR 2007/2008) and unsustainable development, but also how they try to take to the rulers, political leaders, civil society organizations, among other agents, a proposal to build guided actions and procedures based on the need to overcome human insecurity in which all the poorest individuals are immersed and thus lacking income (which would ensure that the basic needs are fulfilled) as well as access to education, health, sanitation, drinking water, housing, employment opportunities, fertile land, political participation and freedom in general.
\end{abstract}

Keywords: human development and security, multi-dimensional aspects, United Nations

$* * *$

\section{Introdução}

A história da noção de segurança humana, nos moldes discutidos no limiar do século XXI, está estreitamente ligada aos Relatórios do Desenvolvimento Humano (RDHs), encomendados, desde 1990 pelo Programa de Desenvolvimento das Nações Unidas (PNUD). Há cientistas sociais (Pureza, 2009; Cravo, 2009) que consideram que o RDH de 1994 "foi o instrumento fundador do conceito de segurança humana” (Pureza, 2009, p.28). O RDH de 2006 fazia a seguinte afirmação:

"Há pouco mais de uma década, o Relatório do Desenvolvimento Humano [de] 1994 introduziu a ideia da segurança humana no debate mais genérico sobre o desenvolvimento. O objetivo era olhar mais além das estreitas percepções da segurança nacional, definida em termos de ameaças militares e da proteção de objetivos estratégicos de política externa, em direção a uma visão de segurança enraizada nas vidas das pessoas” (PNUD/RDH, 2006, p.11).

Desde 1994, os formuladores destes documentos passam a veicular um significado de seguridade que está ainda em construção ${ }^{1}$. Teresa Cravo (2009) afirma que a noção de segurança está sendo posta, de alguma forma, nos últimos anos, em direção às pessoas. Deste modo, o conceito segurança humana refere-se não só a unidades como o Estado, a região e o continente, entendidos em razão de seu poder militar e belicoso capaz de afugentar aqueles que colocariam em risco as fronteiras, os territórios, a cultura e o modo de vida não só das populações de uma circunscrição jurídica e política, mas também dos diversos agrupamentos humanos que podem ter a segurança abalada pelas condições de pobreza, de miserabilidade, de não-acesso à água, ao saneamento, à moradia 
adequada, aos bens de saúde, à educação, à participação política e às liberdades.

\begin{abstract}
"Por oposição à visão minimalista de segurança dominante até então, no nível da origem (externa) e da extensão (militar) da ameaça, o novo conceito propõe um alargamento que permite abranger as causas de insegurança do pós-Guerra Fria, assumindo-se, assim, que as ameaças identificadas dizem respeito a todas as pessoas, em todos os domínios que possam afetar a satisfação de suas necessidades básicas, no que diz respeito à preocupação universal, não obstante o grau de variação em termos de gravidade” (Cravo, 2009, p.71).
\end{abstract}

Observe-se que para esta autora a noção de seguridade foi alargada e não, inteiramente, redefinida. Isto quer dizer que a sua nova formulação contém os elementos antigos pautados na militarização e na belicosidade, mas houve, todavia, uma ampliação daquilo que se entende por elementos definidores da condição de insegurança humana. Veja-se o que afirma os elaboradores do RDH de 2006:

“No (...) início do século XXI, os problemas nacionais de segurança têm um forte peso na agenda internacional. Conflitos violentos, preocupação com ameaças terroristas, (...) proliferação de armas nucleares e (...) crescimento da comercialização ilícita de armas e drogas representam desafios de peso. [Em] face [deste] cenário, é fácil perder de vista alguns imperativos básicos de segurança humana, incluindo os que se relacionam com a água. O número de 1,8 [milhão] de mortes infantis anuais relacionadas com a água imprópria para consumo e com saneamento inadequado ofusca as mortes associadas aos conflitos violentos. Nenhum ato de terrorismo gera uma devastação econômica [na mesma] escala da crise da água e do saneamento. No entanto, a questão mal é aflorada na agenda internacional” (PNUD/RDH, 2006, p.12).

Este artigo tem como objeto, então, não só as associações feitas pelos formuladores dos RDHs entre a insegurança humana, a crise da água e a ausência de saneamento, mas também as correlações estabelecidas entre a inseguridade humana e as drásticas alterações climáticas. Os elementos destacados, no interior dos RDHs de 2006 e 2007/2008 são mostrados como algo capaz de explicar a insegurança humana vivenciada, de modo multidimensional, por diversos agrupamentos de pessoas nas várias partes do planeta.

A exposição desses elementos é feita através de algumas estratégias argumentativas, utilizadas no interior dos RDHs, para convencer governantes, lideranças políticas, organizações da sociedade civil, intelectuais, técnicos e associações de muitas naturezas acerca da necessidade de uma compreensão melhor das razões socioambientais que levam a uma situação de inseguridade humana, quase que generalizada no mundo atual. 
Pretende-se averiguar, em razão do contexto histórico atual, de que questões, elementos e fatores essas estratégias argumentativas, presentes no interior dos RDHs, lançam mão para chamar a atenção de diversos agentes sociais (governantes, técnicos, intelectuais, setores organizados da sociedade civil, entre outros) sobre a necessidade de redefinir ações e procedimentos políticos capazes de, no decorrer das próximas décadas, combater a insegurança humana que assola a vida dos mais pobres.

O problema sociológico que norteará esta discussão será: De quais elementos os elaboradores dos RDHs globais ${ }^{2}$, editados na segunda metade da década de 2000, lançam mão para convencer os governantes e as diversas associações e organizações da sociedade civil de que a insegurança humana é resultante da possibilidade de as pessoas não somente serem atingidas por diversas formas de violência física, mas também de serem afetadas pelas condições de vulnerabilidade e pobreza ${ }^{3}$ agravadas tanto pela escassez de água potável e pela falta de saneamento básico quanto pelas mudanças climáticas que tendem a dificultar mais e mais a vida de uma parte expressiva da população do planeta?

\section{Uma abordagem histórico-hermenêutica dos relatórios: breves considerações}

Será feita, neste artigo, uma abordagem histórico-hermenêutica dos relatórios e isso exige que os textos sejam examinados de acordo com o contexto social e histórico no qual são elaborados. O debate sobre (in) segurança humana emergiu com bastante força, nos RDHs e fora dele, no final do século XX e no início do XXI. Há que se terem em conta os jogos configuracionais - como um "entrançado flexível de tensões” (Elias, 1999, p.142) - entre nações, estados, organismos internacionais, organizações da sociedade civil e lideranças políticas diversas, para entender a construção de argumentações e de narrativas em prol da associação entre desenvolvimento e segurança humanos.

Os elos de interdependência entre os estados e as Nações Unidas mostram as inúmeras complexidades que sustentam as argumentações dos produtores dos RDHs acerca da necessidade e da (im)possibilidade de expandir a faixa de seguridade humana de modo que ela seja capaz de alcançar as populações mais pobres do planeta, as quais vivenciam, cotidianamente, uma multiplicidade de situações de inseguridade material (situações expressas através da pobreza extrema, do não acesso à moradia, a saneamento, a vacinas, a medicamentos, a escolas) e imaterial (inseguridade por preconceitos, discriminações, estigmas, vulnerabilidade, falta de expectativa, de perspectiva, desqualificação e sofrimento social diverso $\left.{ }^{4}\right)^{5}$.

Considera-se, então, que a análise histórico-hermenêutica, como aporte metodológico, ${ }^{6}$ requer procedimentos de pesquisas, como os adotados por John B. Thompson (1995, p.365), que deem conta tanto do 
contexto sócio-histórico e da análise dos argumentos textuais quanto da interpretação, à luz das interações sociais e políticas entre as diversas figurações (estados, organismos internacionais, organizações da sociedade civil) e, assim, permitam desvendar os sentidos e os significados dos diagnósticos e das prescrições, feitos nos RDHs, para a constituição de caminhos que possibilitem promover concomitantemente desenvolvimento e segurança humanos.

Este artigo quer compreender ${ }^{7}$ o que o empenho em alcançar tal concomitância, proposto no interior dos relatórios editados entre 2006 e $2008^{8}$, significa social e politicamente. Portanto, não serão tomados, de modo isolado, para esta análise, as narrativas, os argumentos, as ideias e as experiências tidas como favoráveis ao desenvolvimento humano (arroladas no interior dos RDHs). Todos eles fazem parte de um contexto sócio-histórico formado por jogos configuracionais tensivos, flexíveis, diversificados e interdependentes (Elias, 1998, p.1999).

Como a proposta de análise dos RDHs, expressos em documentos escritos, passa pela análise textual, esclarece-se que não serão tomados os argumentos, as narrativas acerca do desenvolvimento e da segurança humanos como se fossem portadores de uma autonomia em relação ao contexto social no qual se pretende alcança- $\operatorname{los}^{9}$. Não fará, então, uma investigação que se circunscreverá aos elementos sintáticos e semânticos. Os muitos significados e sentidos (direções) dos argumentos postos no interior dos relatórios têm de ser analisados à luz das condições internas e externas que os tornam possíveis.

O processo de constituição da narrativa, constante nos RDHs, acerca do desenvolvimento e segurança humanos, não pode ser compreendido caso se renuncie, inteiramente, a dimensão textual e/ou formal, já que esta última é uma dimensão relevante de toda análise hermenêutica pautada numa epistemologia que considera que "a linguagem ocupa um papel central [uma vez] que não existe conhecimento sociológico que não passe [pela] linguagem, [a qual é sempre] situada” (Melucci, 2005, p.33). Ou seja, "tudo o que é dito, é dito para alguém em algum lugar” (Melucci, 2005, p. 33).

\section{A busca por segurança humana nos RDHs editados na década de 1990 e no início da de 2000: alguns elementos para a compreensão dos relatórios de 2006 e 2007/2008}

Os contrastes sociais são apontados nos RDHs da década de 1990 e 2000 como fatores da insegurança humana que afetava também os países ricos $^{10}$ e não somente os mais pobres. Seguidamente, os formuladores dos RDHs procuravam demonstrar que as ameaças se produziam em todas as dimensões e atingiam países, continentes, regiões e o planeta como um todo. Por isso, era preciso ter mais e mais claro que “a busca de seguridade 
humana deve efetuar-se através do desenvolvimento e não mediante as armas” (PNUD/RDH, 1994, p. 1).

A inseguridade humana é caracterizada, no RDH de 1994, como uma ameaça que pesa sobre todos indistintamente. Aquecimento global, pobreza extrema, mudanças climáticas drásticas, terrorismo, contaminações de solos e águas, perigos nucleares, proliferação de vírus (na época havia uma preocupação recorrente com Aids) e destruição do meio ambiente podem trazer consequências drásticas para todos, insistiam os elaboradores do RDH de 1994.

Pode-se dizer que os formuladores e encampadores (técnicos do PNUD) dos relatórios mobilizavam diversos elementos para atestar, nos derradeiros anos do século XX, que a humanidade era interdependente e encontrava-se ligada de diversas formas, ainda que muitos grupos pareciam caminhar quase indiferentes a essa condição. Acredita-se que, ao mobilizar a noção de inseguridade humana, o PNUD, como um órgão do sistema das Nações Unidas, buscava trazer à baila algo que tem estado presente desde a criação de uma instituição global como a ONU. Norbert Elias ressalta:

“A crescente integração da humanidade [e] a progressiva interdependência de todos os subgrupos humanos [que] se manifestam não apenas numa série de instituições globais tais como o Banco Mundial e a Organização das Nações Unidas, mas também em tensões e conflitos específicos relacionados a esse contato mais intenso" (Elias, 2006, p.62).

O que se observa nas primeiras duas décadas do século XXI é que ocorre, no interior dos RDHs, uma crescente vinculação dos diagnósticos acerca da ampliação da insegurança humana às situações de inobservância dos direitos (PNUD/RDH, 2000) que se refletem não somente nas condições de violência física e de penúria material, mas também de outras violências e precariedades expressas em discriminações, preconceitos (PNUD/RDH, 2004) e não-acesso à participação política (PNUD/RDH, 2002), à saúde, à escolarização, ao manejo de novas tecnologias (PNUD/RDH, 2001), à moradia, água e saneamento adequados (PNUD/RDH, 2006). Entra em cena, com força significativa, a vinculação entre seguridade humana e democracia. O relatório publicado em 2002, após o ataque às torres gêmeas nos EUA, tinha como título "Aprofundar a democracia em um mundo fragmentado".

Nele ressaltava-se que o caminho para a segurança humana era o caminho da democracia, o que pode parecer um elogio ao Ocidente e a suas instituições. No entanto, ainda que isso seja, de alguma forma, uma mensagem presente, o que parecia mais evidente era que o combate ao terrorismo devia fazer-se com melhoramento do bem-estar, com o combate à pobreza, com a geração de habilidades e capacidades profissionais e políticas e com o fortalecimento dos direitos humanos e das instituições democráticas. Assinale-se, no entanto, que há, no interior do RDH de 2002, um 
capítulo que se intitula "Democratizar a segurança para evitar os conflitos e consolidar a paz”. Nele o debate sobre segurança situa-se, essencialmente, no campo da contenção do conflito, da violência física e da guerra.

Os formuladores do RDH de 2002 construíam uma narrativa sobre a diferença entre segurança e democracia e segurança e autoritarismo. Eles tentavam demonstrar com dados, exemplos e menções a casos específicos que os regimes ditatoriais não conseguiam evitar, desarmar e/ou conter os conflitos violentos e as lutas internas. Ou melhor, não havia possibilidade alguma de construir um mundo menos belicoso e menos violento, caso não fossem desmontadas as práticas, as instituições, as ações e os procedimentos autoritários que poderiam ser encontrados tanto nos países tidos como democráticos quanto naqueles reconhecidamente ditatoriais.

Note-se que os encampadores dos relatórios estavam preocupados com os rumos que o planeta estava tomando no limiar do século XXI em relação ao aumento da belicosidade, dos conflitos e das guerras. A situação em que o mundo se encontrava baixava a zero as expectativas de ampliação do desenvolvimento humano. As intervenções de segmentos armados em assuntos políticos, as quais tendiam a exacerbar-se nos anos subsequentes, eram apontadas como preocupantes por aqueles que defendiam a constante construção de instituições democráticas.

“Tanto nos países democráticos como nos países não-democráticos, partes do setor da segurança podem tornar-se instrumentos de políticos ou partidos extremistas. Ou podem, na realidade, cair em mãos privadas - como senhores da guerra, grupos paramilitares ou empresas de segurança privadas. Além disso, os serviços de segurança legítimos são muitas vezes incapazes de lidar com o aumento da criminalidade, com as violações dos direitos humanos ${ }^{11}$ ou com a violência étnica” (PNUD/RDH, 2002, p. 87).

Nesse relatório de 2002, editado logo após o ataque às Torres Gêmeas nos EUA, houve empenho em situar o debate sobre insegurança no campo mais circunscrito da militarização e da belicosidade que acabava por arrasar a vida dos mais pobres, impedidos, muitas vezes, pelos conflitos e perseguições, de realizar as atividades diárias que garantissem seu sustento. Lutar pelas liberdades básicas ficava, então, inteiramente impossível para aqueles que viviam em regiões tomadas por guerras, conflitos e limpezas étnicas. As condições de pobreza extrema somadas às situações de perseguição, de preconceitos, de conflitos étnico-raciais e de perseguição e intimidação por parte de forças policiais a serviço daqueles que estão no poder formavam, então, um quadro sombrio e desesperador para partes da população do planeta.

Os elaboradores do RDH de 2002 afirmavam que era necessário averiguar o que estava por trás do conceito segurança nacional (PNUD/RDH, 2002, p. 89). Nele poderiam esconder-se os mais escusos interesses pessoais, grupais ou de países. O mercado mundial de armamentos era "sustentado 
por poderosos interesses econômicos [e] reforça[va] o secretismo excessivo e a corrupção nos setores de segurança de muitos países” (PNUD/RDH, 2002, p.89). Os argumentos arrolados neste documento eram complementados com dados sobre a amplíssima dianteira dos Estados Unidos no mercado exportador de armas convencionais entre 1996 e 2001.

Os extremismos violentos eram mostrados como frutos de uma situação mundial enaltecedora da violência, do conflito e da belicosidade. A insegurança humana parecia, nos relatórios de 2002, 2003 e 2004, desencadeada tanto por interesses armamentistas, políticos e econômicos, quanto por situações de pobreza extrema (PNUD/RDH, 2003), de preconceitos e de discriminações das mais diversas naturezas (PNUD/RDH, 2004). Todavia, a insegurança humana tendia, segundo os produtores e encampadores dos RDHs de 2006 e de 2007/2008, a se expandir em virtude da escassez da água, das alterações climáticas e das políticas de desenvolvimento arrasadoras do meio ambiente.

\section{Os RDHs de 2006 e 2007/2008: a insegurança humana decorrente da escassez de água, das mudanças climáticas, das vulnerabilidades e das práticas econômicas insustentáveis}

A Assembleia Geral das Nações Unidas, desde 2005, tem realizado debates que apontam para a necessidade, a partir de seus encontros mundiais de cúpula, de elaborar alguns documentos que fossem tornando mais e mais preciso o conceito de segurança humana (Reports of the S-G on Human Security, 2010; 2012; 2013).

Esclarece-se que tais documentos davam prosseguimento às discussões levantadas na Declaração do Milênio (2000) que estabelecia um conjunto de metas e objetivos a serem buscados pela ONU e por todos os países constituintes do sistema das Nações Unidas. O item dois desta Declaração tratava, especificamente, das metas que deveriam ser buscadas para evitar genocídios, democídios ${ }^{12}$ e extermínios de diversas naturezas, perpetrados pelas mais variadas motivações.

Os Relatórios da Secretaria Geral das Nações Unidas, intitulados A segurança Humana, estavamvoltados para dois objetivos básicos: tornar mais preciso o que se deveria entender por segurança humana e tornar mais evidente quem deveria, diretamente, zelar pela sua busca. Os governantes são apontados no Reports of the S-G on Human Security, (2010) como aqueles que devem garantir sobrevivência digna para todos os cidadãos.

Como são muitas as ameaças que pairam sobre as pessoas, os dirigentes devem, como consta neste documento, ter a capacidade de perceber quais são as ameaças que se avizinham bem como intervir no sentido de evitá-las. As catástrofes coletivas que se anunciam têm de ser contidas. 
Entre elas, o documento cita a necessidade de enfrentar a insegurança alimentar provocada pelas catástrofes climáticas e a insegurança decorrente do não-acesso à saúde, à educação e aos processos participativos.

Ganha destaque no interior dos Reports of the S-G on Human Security, (2010; 2012; 2013) o alerta para a necessidade da conscientização de que as condições de inseguridade humana entrelaçam todas as partes do mundo. Os perigos são múltiplos, multifacetados e multidimensionais de tal maneira que algo tido como circunscrito a alguns povos pode, sem demora, estender-se para regiões e localidades inimagináveis. Os efeitos das secas, das mudanças climáticas, da falta de água e de alimentos e os relacionados às crises epidêmicas mostram, na atualidade, o quanto os diversos povos estão interligados, conforme ressaltam os elaboradores dos relatórios, mencionados no início deste parágrafo, da Secretaria Geral da ONU.

Os formuladores do RDH de 2006, intitulado A Água para além da escassez: poder, pobreza e a crise mundial da água, davam maior consistência às questões socioambientais que têm aumentado a insegurança humana dos indivíduos mais empobrecidos do planeta. Refutando um entendimento convencional de que há somente escassez da água e, portanto, todos estavam à mercê de tal situação, os elaboradores deste documento afirmavam que o problema não poderia ser tomado no sentido difundido por Malthus ${ }^{13}$, defensor da ideia de que o futuro estaria fundado na escassez de alimentos em vista da expansão do número de habitantes do planeta terra. Eles diziam que esta noção de escassez estava muito presente "nos debates internacionais sobre a água” (PNUD/RDH, 2006, p.10).

"Rejeitamos este ponto de partida. A disponibilidade de água é uma preocupação para alguns países. Mas a escassez que se encontra no coração da crise mundial da água tem as suas raízes no poder, na pobreza e na desigualdade, não na disponibilidade física” (PNUD/ $\mathrm{RDH}, 2006, \mathrm{p} .10)$.

A pergunta posta no documento era: Há escassez e/ou má distribuição da água? Antes de abraçar a tese de que a água estava minguando, era necessário enfrentar um problema político da mais alta relevância, ou seja, a péssima distribuição da água. Esta última seria "o cerne de uma crise diária que afeta vários milhões de pessoas mais vulneráveis do mundo - uma crise que ameaça a vida e destrói os meios de subsistência [em] escala arrasadora” (PNUD/RDH, 2006, p.10).

Os produtores e encampadores do RDH de 2006 ressaltavam que o debate atual sobre a escassez de água ofuscava o fato de que a inacessibilidade à água repercute "uma crise silenciosa suportada pelos pobres e tolerada por aqueles que dispõem de recursos, tecnologia e do poder político de acabar com ela” (PNUD/RDH, 2006, p. 9). A dimensão que tomava a discussão sobre a escassez da água fazia parecer que todos os segmentos, grupos e indivíduos estavam nas mesmas condições pela possibilidade de que a água potável torne cada vez menos acessível. 
Este tipo de posição, que ganhava asas no debate internacional, segundo eles, impedia a formação de um conhecimento mais acurado sobre como ocorrera a sua distribuição ao longo de décadas. Eles afirmavam que os mais pobres vinham sendo afetados, há décadas, pelo não-acesso à água potável e pela deficiência do esgotamento sanitário ${ }^{14}$. Não levava, então, a nenhum resultado olhar a questão somente pelo lado da escassez, já que durante muitos anos teria havido escassez para alguns (os mais pobres) e abundância para outros (os mais ricos).

“No entanto, esta é uma crise que está a bloquear o progresso humano, condenando uma considerável parte da humanidade a vidas de pobreza, vulnerabilidade e insegurança. Esta crise ceifa mais vidas por doenças do que qualquer conflito armado. Reforça também as obscenas desigualdades nas oportunidades de vida que dividem nações ricas e pobres (...) e também as de um mesmo país com base na riqueza, gênero e outros indicadores de desvantagem” (PNUD/ RDH, 2006,p. 9).

A crise da água e a inexistência de saneamento são mostradas como capazes de subtrair das pessoas mais pobres anos e anos de vida e também a possibilidade de terem uma vida livre de doenças evitáveis, mas que, por não serem evitadas, dificultam-lhes o processo de aprendizado e as privam de uma vida saudável. Em condições de habitação insalubre, as crianças têm suas chances educacionais extremamente reduzidas, uma vez que adoecem com frequência e são humilhadas pela situação de vulnerabilidade extrema ${ }^{15}$. Esse tipo de reflexão tem sido feito, há anos, por diversos cientistas.

"Falta de esgoto impacta a inteligência das pessoas por causa de infecções parasitárias na infância. (...) O cérebro é o órgão do corpo humano que mais consome energia: $87 \%$ no recém-nascido, $44 \%$ aos cinco anos, 34\% aos dez. As infecções parasitárias desviam energia para ativar o sistema imunológico. Repetidas diarreias até os cinco anos roubam do cérebro as calorias necessárias a seu desenvolvimento, comprometendo a inteligência para sempre. É pura ilusão, portanto, supor que não sejam pobres pessoas que padecem dessa catastrófica privação que é o permanente risco de contrair parasitose, só porque [têm] renda superior a x reais” (Veiga, 2011, p.3).

Os alicerces de um desenvolvimento que garante a segurança humana, conforme argumentavam os elaboradores do relatório de 2006, seriam o acesso à "água potável, a eliminação das águas residuais e a oferta do saneamento" (PNUD/RDH, 2006, p.10). Sem esses três pilares as pessoas ficam com suas chances reduzidas de permanência na escola, de serem saudáveis e de obterem empregos.

É interessante assinalar que os formuladores do RDH de 2006 construíam uma narrativa distinta da daqueles que tendiam a ver sinais apocalípticos de catástrofes iminentes em razão da escassez da água e das 
ásperas mudanças climáticas. O documento em questão tentava desmantelar esse tipo de argumento com a construção de uma abordagem mais política e institucional. E o fazia dando destaque ao modo como as políticas públicas acabavam, em várias partes do mundo, por promover uma má distribuição tanto da água como dos serviços de esgoto e saneamento.

Havia empenho em rebater as falas apocalípticas - de acordo com as quais não há como encontrar solução nem para os problemas existentes nem para os que se avizinham - com argumentos baseados em dados sobre percentual de pessoas sem acesso a água potável, sem acesso a saneamento e achacadas por diversas doenças provenientes de tais condições. Ganhavam também destaque, no RDH de 2006, os altos números de mortes de crianças por diarreia, o percentual de redução da mortalidade infantil, quando há políticas sanitárias implementadas, e o fato de que são as pessoas mais pobres as mais atingidas pela falta de água e de saneamento.

Em muitas partes do mundo, não em todas evidentemente, o grande problema era a má distribuição da água não a sua escassez, é o que apontava o relatório. A divisão da água era feita, quase sempre, de modo a favorecer alguns segmentos em detrimento de outros. No Benin, em 2001, enquanto $90 \%$ dos 20\% mais ricos tinham acesso à água, pouco mais de $10 \%$ dos $20 \%$ dos mais pobres tinha tal acesso. No Peru 100\% dos 20\% mais abastados tinham acesso à água, ao passo que somente $1 / 4$ dos $20 \%$ mais pobres o teria (PNUD/RDH, 2006, p.17).

Os elaboradores do RDH de 2006 comparavam também os gastos militares com os outros gastos, tais como, os gastos com educação, saúde, água e saneamento. Em alguns lugares (Etiópia, Iêmen, Paquistão, Índia) constatava-se uma maior destinação dos recursos para os gastos militares. Em outros (África do Sul, México, Zâmbia) evidenciava-se um investimento maior em serviços de saúde; todavia, em água e saneamento os índices de investimentos eram baixíssimos em vários países (PNUD/RDH, 2006, p.21).

Ao verificar o baixo investimento em serviços de água e saneamento, em diversas partes do mundo, os elaboradores do documento passam a fazer uma série de considerações sobre o papel do setor público e do privado na melhoria de tais serviços. Note-se que, neste relatório, se insiste no fato de que a privatização da água, conforme fora elogiada em relatórios da década de 1990 (Dagdeviren e Hailu, 2008), ${ }^{16}$ havia sido problemática em muitas partes do mundo.

Havia ainda certo receio em admitir que o fracasso dos processos de privatização dos serviços de água deveria ser, abundantemente, discutido. Por essa razão, a saída encontrada pelos formuladores do RDH de 2006 foi a seguinte: separar o acesso à água, que nos países com níveis altos de pobreza deveria ser garantido pelo poder público, do fornecimento.

Assim, deveria ser facilitado e ampliado em prol dos mais pobres o acesso aos serviços de água, através dos investimentos públicos, enquanto 
que o fornecimento poderia ser tanto público quanto privado (PNUD/RDH, 2006, p.21). O Estado deveria, então, construir a infraestrutura de acesso e o setor privado obteria altos lucros por meio do fornecimento. No Brasil, onde vigora o que Raymundo Faoro (1988) denominou de capitalismo politicamente orientado, é muito fácil prever o resultado de processos desta natureza ${ }^{17}$.

Consta, então, no RDH de 2006 que, se a preocupação é com a ampliação da segurança humana, e o acesso à água é essencial para que esta ampliação seja garantida. A questão essencial não consistia em ser público e/ou privado o fornecimento e acesso à água, mas sim o quanto estava sendo ampliado o acesso às pessoas mais pobres. Não há dúvida de que os argumentos e a narrativa utilizados pelos RDHs, e não somente por este de 2006, são dúbios em relação ao papel que caberia ao Estado na realização de políticas capazes de elevar o grau de segurança humana. Hesitase sobre que orientações seguir em relação ao que deve ser realizado pelo setor público e ao que deve ser executado pelo setor privado.

Em alguns momentos, nota-se uma narrativa favorável a este último. Parece haver uma linha, não muito explícita que pende para uma postura geradora de dúvidas acerca da eficácia do Estado na criação de políticas de segurança humana. Na introdução ao RDH de 2006 há um subitem que se intitula Segurança humana, cidadania e justiça socialno qual se insiste que, sem acesso à água, não há segurança humana.

Por isso, a discussão gira em torno muito mais do acesso do que do fornecimento. Ou seja, como e quem deve garanti-lo? O Estado entra aí como um dos agentes relevantes, porém não único. Pode-se perguntar: Ao separar-se acesso de fornecimento não se criariam brechas favoráveis a agentes privados que encontrariam pronto todo um sistema de infraestrutura de fornecimento de água para explorar?

Desse modo, pode-se dizer que há dois conjuntos de argumentos, no que tange ao desenvolvimento e à segurança humana, que continuam interligados. Um diz respeito aos embates sobre quais agentes têm maior credibilidade para encabeçar um amplo e duradouro processo de alargamento das zonas de segurança das pessoas e não somente de nações, países e territórios, e o outro que tende a ampliar a crença de instituições e associações da sociedade civil, acerca da necessidade de compartilhar ações e tarefas capazes de promover melhorias asseguradoras de uma maior segurança humana.

No que tange à segurança nacional há, como dizem os produtores do RDH de 2006, uma agenda internacional que dela se ocupa propondo ações relacionadas a algumas ameaças, como o vírus VIH/SIDA (Aids); há também algumas ações concertadas em torno de alguns objetivos como o que ocorreu no enfrentamento do vírus H1N1 que acabou por mobilizar "um plano de ação global” (PNUD/RDH, 2006, p.12). 
No entanto, no que diz respeito à situação do não-acesso à água e ao saneamento não se vê mobilização para criar uma agenda de ações e procedimentos com o intuito de encontrar soluções. E por que as coisas se passam desta maneira? Porque "a crise da água e do saneamento representa [uma] ameaça mais imediata e mais direta às pessoas [carentes] dos países pobres - um eleitorado sem voz na formação das percepções internacionais da segurança humana” (PNUD/RDH, 2006, p.12).

Essas são razões mais do que suficientes para entender, na opinião dos elaboradores do RDH (2006, p.12), que "a insegurança [por indisponibilidade] da água viola alguns princípios básicos da justiça social”, tais como os de cidadania, uma vez que é negado a uma parte da população do planeta "um conjunto igual de direitos civis, políticos e sociais" (PNUD/RDH, 2006, p.12). Eles acrescentam:

“A insegurança [pelo não-acesso à] (...) água compromete estes direitos. Uma mulher que passa horas a fio a recolher água ou que sofre de constantes doenças relacionadas com [à carência da] água tem menos capacidade de participar na sociedade, mesmo que possa participar da eleição do seu governo. (...) A igualdade de oportunidades, um requisito-chave para a justiça social, é diminuída pela insegurança [de acesso à] água. A maioria das pessoas aceitaria que a educação é essencial para a igualdade de oportunidades. Por exemplo, as crianças impossibilitadas de frequentar a escola quando se encontram afetadas por (...) constantes (...) doenças causadas por água imprópria para consumo não usufruem, em qualquer sentido positivo, do direito à educação. (...) A forte desigualdade no acesso à água potável doméstica ou à água produtiva no campo não cumpre os critérios de distribuição justa, especialmente quando associada aos elevados níveis, evitáveis, de mortalidade infantil ou de pobreza” (PNUD/RDH, 2006, p. 12).

O RDH de 2007/2008, intitulado Combater a mudança no clima: solidariedade humana em um mundo dividido, aponta os diversos riscos e perigos que a humanidade, em muitas partes do mundo, está correndo em razão das muitas mudanças climáticas. Todavia, ressalta-se, em suas muitas páginas, que a humanidade não é una, mas composta de indivíduos dotados de recursos (materiais e imateriais) muito distintos.

Os segmentos mais abastados vivenciam as mudanças climáticas que levam a secas, a enchentes, à desertificação e à improdutividade dos solos sem sofrimentos porque têm como suportá-las, enquanto os setores mais pobres vivenciam tais fenômenos com muito sofrimento, uma vez que sua vida é afetada pela ampliação das condições de privação e de vulnerabilidade.

No capítulo 4 intitulado Adaptação ao inevitável: ação nacional e cooperação internacional, os formuladores do RDH de 2007/2008 partem do pressuposto de que todos (países e pessoas) terão como desafio, nos 
anos vindouros, a adaptação a um meio ambiente que se vêm transformando expressivamente.

Qual é a questão posta por eles? Esta adaptação se dará de modo distinto, pois há países e pessoas dotadas de maiores recursos para se colocar diante de mudanças extremamente preocupantes. Quais têm sido os mais afetados? Os países pobres e as pessoas pobres é sua resposta.

Quanto mais alguém é vulnerável tanto mais é obrigado a lutar sozinho contra as intempéries da natureza. Secas, enchentes e furações arrasam a vida das populações miseráveis, as quais não têm como contar com ajudas financeiras dos governos locais. "A desigualdade na capacidade adaptativa [surge] como um condutor virtual de disparidades ainda mais vastas em áreas como a saúde, segurança ou oportunidades de desenvolvimento humano”(PNUD/RDH, 2007/2008, p. 167).

Em razão das condições de adaptação desiguais, os formuladores deste relatório abraçavam duas propostas: uma pautada na necessidade de estabelecimento de um processo amplo de cooperação internacional que contribuísse com países, continentes e regiões pobres para a construção de uma infraestrutura capaz de diminuir a perversidade dos efeitos destrutivos das mudanças climáticas, as que, em alguns momentos deste $\mathrm{RDH}$, parecem irreversíveis. Há que encontrar formas de lidar com elas. A outra proposta se assenta na busca da capacitação de "pessoas para gerirem os riscos climáticos sem sofrerem recuos no desenvolvimento humano" (PNUD/RDH, 2007/2008, p.168).

Os efeitos das mudanças climáticas são, neste capítulo 4, tidos como inevitáveis, restando apenas adaptações a tal situação. Pode-se perguntar: Este tipo de narrativa, de argumentação não acaba por reforçar atitudes, expectativas, perspectivas, interesses, disposições, valores e uma cultura que foca essencialmente os efeitos e não as causas?

Ao dizerem que "a mitigação faz parte de uma estratégia dual para a segurança” (PNUD/RDH, 2007/2008, p.168) humana, não estão tentando construir soluções paliativas que dispensam confrontos maiores com os interesses daqueles países, segmentos e grupos que se têm eximido de observar as recomendações, agendas e tratados internacionais sobre o meio ambiente? Obviamente, as coisas são muito mais complexas quando se lança um olhar mais atento sobre os relatórios de 2006 e 2007/2008 que condensam grande parte das discussões sobre (in) sustentabilidade dos padrões de organização socioeconômicos atuais.

Ainda que não seja possível realizar uma análise extensiva do relatório de 2007/2008 como um todo, deve-se considerar que ele foi construído da seguinte maneira. O capítulo 1 destacou os desafios climáticos e suas consequências para o desenvolvimento humano. Nesta parte há, sem dúvida, uma preocupação com as causas das mudanças climáticas que afetavam, em especial, os mais empobrecidos que dependem da água, do clima 
adequado, do solo, das florestas, dos lagos, dos rios, entre outros, para obter o sustento.

A insegurança humana torna-se, para estas pessoas, muito penosa. Por essa razão, os elaboradores deste RDH discutem a promoção de ações políticas capazes de definir uma agenda de medidas urgentes, no campo econômico, para que sejam adotados procedimentos de combate aos fatores (emissão de carbono, por exemplo) que acentuam as drásticas alterações do clima em várias partes do planeta.

Tendo como objetivo chamar a atenção para os efeitos do clima sobre o aumento da vulnerabilidade, da pobreza e da miserabilidade, os produtores e encampadores dos relatórios procuram explicar o modo como os desastres climáticos criam inúmeras armadilhas que dificultam o cumprimento das metas do milênio e do desenvolvimento humano, pois tendem a exacerbar as privações dos segmentos que vivem em situação de pobreza extrema.

Alertam, então, para os crescentes riscos e perigos decorrentes do descumprimento das metas sociais globais e regionais. Norbert Elias (2006) enfatiza que é necessário atentar para a confusão que, muitas vezes, se faz entre risco e perigo. Quais são os riscos reais das alterações climáticas paralisarem o processo de busca pelo desenvolvimento humano? Quais são os perigos de que isso ocorra?

Se houver confusão entre risco e perigo a discussão política pode perder-se em generalidades. Os segmentos mais pobres correm continuamente o risco de não ter garantia alguma de sobrevivência. As mudanças climáticas dão concretude a esta situação? Onde se situam os perigos sociais, econômicos e políticos que se delineiam no horizonte? Estariam eles nas práticas e procedimentos dos agentes detentores de poder e de recursos (político, econômico, social)? Têm os agentes políticos, as lideranças da sociedade civil, os técnicos, os governantes, entre outros, disposição para enfrentar os perigos da insegurança alimentar que tende a atingir, muito mais fortemente, os mais pobres?

Essas questões, ainda que incipientes, aparecem, ora mais ora menos acentuadamente, nas preocupações daqueles que elaboraram o RDH (2007/2008). Todavia, não há dúvida de que há, conforme consta no documento, uma evidente dificuldade de enfrentamento dos muitos interesses políticos que estão na base da inseguridade humana derivada dos desastres climáticos e ambientais, de modo geral.

“Apesar dos pobres não conseguirem abrir caminho, através da adaptação, para escapar aos perigos das alterações climáticas, o impacto do aquecimento global pode ser atenuado através de políticas benéficas. No que se refere à adaptação, as decisões tomadas à partida podem reduzir os riscos e limitar os danos no desenvolvimento humano, causados pelas alterações climáticas. Os governos dos 
países do norte desempenham um papel fundamental. Quando assinaram a Convenção Quadro das Nações Unidas sobre as Alterações Climáticas (CQNUAC) em 1992, estes governos concordaram em ajudar 'os países em vias de desenvolvimento, particularmente vulneráveis aos efeitos adversos das alterações climática (...)’. Após 15 anos, essa promessa ainda não foi cumprida. (...) Em suma, a estrutura atual fornece o equivalente a uma esponja que ajuda a absorver a água durante uma inundação” (PNUD/RDH, 2007/ 2008, p. 168).

Há duas questões que estão na base dos RDHs que se ocupam da insegurança humana decorrentes das alterações climáticas atuais. Uma diz respeito à adaptação, por parte dos governantes, técnicos e gestores, das políticas de construção de infraestrutura para reduzir a vulnerabilidade das populações mais pobres ${ }^{18}$. A outra refere-se ao modo como estas últimas se adaptam aos riscos a que estão expostas em razão das variações climáticas em curso, visto serem elas as mais ameaçadas por riscos progressivos (PNUD/RDH, 2007/2008: 169). E o que mais chama a atenção no interior deste relatório é o modo como utilizam a abordagem das capacidades para enfrentar os problemas ambientais.

"Capacitar as pessoas para gerirem esses riscos requer políticas públicas que possam criar resiliência, através de investimentos em infraestrutura, segurança social e melhor gestão de riscos. É, também, necessário um compromisso mais sério de políticas abrangentes, que sustente o desenvolvimento humano e reduza as desigualdades extremas”(PNUD/RDH, 2007/2008, p.169).

\section{Considerações Finais}

Não há dúvida de que o núcleo central dos RDHs é a tentativa de chamar a atenção de governantes, lideranças políticas, organizações da sociedade civil, de modo geral, para essa condição de interdependência global presente na atualidade. E a questão da insegurança humana acaba sendo um eixo articulador de todas as demais ideias e propostas contidas nos relatórios.

Deve-se considerar que na década de 1990 as prescrições referentes à segurança humana eram mais e mais direcionadas à busca de melhores condições de igualdade entre os sexos (PNUD/RDH, 1995) e à implementação de um crescimento econômico capaz de fomentar o desenvolvimento humano e erradicar a pobreza multidimensional (PNUD/RDH, 1996; PNUD/RDH, 1997), ações que exigiriam novas formas de consumo sustentável e políticas globais não prejudiciais aos países e pessoas pobres como estava ocorrendo naquele momento (PNUD/RDH, 1998; PNUD/RDH, 1999).

Os formuladores dos Relatórios do Desenvolvimento Humano (RDHs) têm utilizado a noção de segurança humana de maneira cada vez 
mais frequente. Neste artigo buscou-se o significado desta noção que emergiu, na década de 1990, no interior destes documentos. Nota-se que ela é mostrada como capaz de sistematizar os muitos aspectos que compõem o desenvolvimento humano.

Nos relatórios foram construídas algumas narrativas que tanto chamam a atenção para as possibilidades quanto para as dificuldades do desenvolvimento humano, pensado no que diz respeito às melhorias nos níveis de renda, escolaridade, longevidade, participação política e liberdades para agir, ser, pensar e decidir sobre o que é melhor para o indivíduo bem como para a coletividade.

É destacado que, conquanto os mais pobres sejam os mais afetados pelas condições de vulnerabilidade (PNUD/RDH, 2014) que os tornam mais atingidos pela insegurança e pela inexistência de planos, projetos e políticas concretas, essas mesmas condições passarão, no curto e médio prazo, a potencializar situações de inseguranças que poderão ameaçar não somente os que já convivem, cotidianamente, com muitos riscos (de não ter alimento, água, moradia, saúde, escola, saneamento, trabalho, integridade física respeitada, acesso à justiça, aos direitos e aos meios de participação política), mas também uma fatia considerável e cada vez maior da população mundial.

Todos os argumentos apresentados nos relatórios dialogam com outras narrativas sobre desenvolvimento e segurança humanos que vão se desenvolvendo no âmbito acadêmico e político (ou seja, em várias instâncias governamentais e da sociedade civil). Parte-se, então, do pressuposto de que os documentos têm de ser examinados em vista de um processo de dupla hermenêutica ${ }^{19}$. Eles influenciam e são influenciados por uma multiplicidade de interpretações, argumentos, narrativas e ações.

Não há dúvida que sobressaem, nas recomendações, as necessidades de os indivíduos se capacitarem para resolver problemas de magnitudes gigantescas. Os produtores dos RDHs mostram-se assim ora enlaçados, de diversas formas, às perspectivas individualizantes (que, como afirma Bauman (2001), encarrega as pessoas de resolver problemas sistêmicos) ora críticos quanto ao modo como muitos grupos de pessoas extremamente pobres estão hoje tendo que se virar por conta própria e lutar diuturnamente contra todos os tipos de ameaças, riscos e inseguranças. Eles dão muitos exemplos de como isto têm ocorrido no Quênia, Vietnã, Índia, Nepal, Bangladesh entre outros. 


\section{Notas}

${ }^{1}$ É evidente que da construção deste significado participam também diversos estudiosos desta temática (Axworthy, 2004; SuhkI, 1999; Kaldor, 2007; Gledhill, 2012)

${ }^{2}$ Existem os RDHs globais, os regionais e os nacionais. Este artigo privilegiará aqueles primeiros.

${ }^{3}$ Deve-se considerar que, embora de modo distinto, este tipo de associação vem sendo feito há alguns anos por diversos cientistas sociais. Sobre isto, ver: (Bauman, 1999; 2005; Furtado, 2001, 2002; Judt, 2011, Sen, 2006, 2010; Therborn, 1999; 2010; Tilly, 1998).

${ }^{4}$ Pierre Bourdieu (2003) e Bauman (1999; 2005) estão entre os cientistas sociais que fazem distinção entre sofrimento individual e sofrimento social. Robert Castel (1998) também problematiza a vulnerabilidade social atual como fragilização dos laços sociais e acirramento dos sofrimentos sociais.

${ }^{5}$ Robert Castel (1998) discute longamente a ampliação das zonas de vulnerabilidade social que potencializam, no dia-a-dia das pessoas, a condição atual de inseguridade individual e social.

${ }^{6}$ Esse brevíssimo esclarecimento sobre os procedimentos de pesquisa não permite alongarmo-nos no debat se a hermenêutica pode, ou não, ser tomada como um aporte metodológico. Sobre isso, ver: (Dilthey, 1942, 1988; Gadamer, 1998; Ricouer, 2000, 1988; Thompson, 1995; Souza Santos, 1989, Soares, 1988, Rudiger, 2009; FloresGalindo, 2009; Bauman, 2010).

${ }^{7}$ O problema da compreensão, de como alcançá-la e através de quais caminhos e meios constitui-se um dos pontos nodais da hermenêutica. Sobre isto, ver: ( Flores-Galindo, 2009; Alves, Rabelo e Souza, 2014; Soares, 1988; Tralhão, 2009).

${ }^{8}$ Em vista da extensão e complexidade das questões tratadas nos RDHs, não é possível abarcar um número maior de relatórios neste momento. Os documentos editados entre 2000 e 2005 foram trabalhados num outro artigo que procurava, também, desvendar a correlação feita por seus formuladores entre desenvolvimento e segurança humana.

${ }^{9}$ Há um leque de teorias da argumentação. Observe-se que nelas em grande medida parte-se em geral do pressuposto de que há uma autonomia do argumento. Por isso ele é posto em primeiro plano na análise sociológica. A análise pode, então, centrar-se nele essencialmente. Ou seja, pode-se realizar uma análise semântica, uma análise sobre controvérsias, sobre audiências e capacidades persuasivas. Pode-se ainda tomar, como fez Toulmin, “o argumento como um organismo” (Santibáñez, 2012, p.4). Neste caso, ele é dotado de vida própria, se reproduz, adoece (as falácias seriam enfermidades que atacam um dado argumento) e envelhece. (Santibáñez, 2012).No caso desta pesquisa, o argumento nunca é tomado isoladamente e/ou autonomamente. Ele é estudado em vista tanto do contexto sócio-histórico no qual é produzido quanto dos jogos configuracionais que o torna possível.

${ }^{10}$ Sobre isto ver, principalmente, os RDHs (1994; 1997; 2003; 2005; 2010; 2011). 
${ }^{11}$ Consta a seguinte passagem no RDH de 2006: "Os direitos humanos não são extras facultativos. Tal como não são uma disposição legal voluntária a abraçar ou abandonar segundo o capricho de cada governo. São obrigações vinculativas que refletem valores universais e implicam responsabilidades por parte dos governos” (RDH, 2006, p. 12).

${ }^{12}$ Democídios seriam as matanças intencionais de populações desarmadas. Esta palavra, utilizada em Portugal, é pouco conhecida no Brasil.

${ }^{13}$ Referente às ideias do pensador social Thomas Robert Malthus (1766-1834) que continuam, de alguma forma, presentes na atualidade. Elas podem ser identificadas nas muitas "descrições de esgotamento de recursos finitos da terra em virtude da explosão da população no mundo” (Levine, 1997, p.275).

${ }^{14}$ Pode-se perguntar: Qual é a situação do Brasil em relação ao saneamento? "O número de moradias insalubres diminuiu dez pontos entre 1995 e 2002 (de 59,1\% para 49,5\%), e mais cinco entre 2003 e 2008 (de 48,3\% para 43\%). Mantidos tais níveis de desempenho, a universalização do esgoto com tratamento só ocorreria em 2060. Se o investimento dobrasse e a produtividade aumentasse um terço, essa meta poderia ser atingida em 2024. (...) Seriam necessários quatro governos bem melhores que os de Lula [2003-2010] para que a pobreza fosse minimizada” (Veiga, 2011, p. 3).

${ }^{15}$ Estas questões eram discutidas já no RDH de 1996. “A moradia adequada relacionase diretamente com o progresso em matéria de saúde, alfabetização e longevidade e com a estabilidade social das comunidades. O melhoramento da moradia impulsiona o bem-estar e a saúde material e psicológica, com a qual se incrementa a produtividade do trabalho e o rendimento escolar. E a localização apropriada dos assentamentos pode ampliar as oportunidades de emprego” (RDH, 1996, p.28)

16 “(...) A proporção da população com acesso à água potável tem reduzido de $72 \%$ em 1992 para 57\% em 2002. A qualidade do acesso também tem deteriorado: aproximadamente $25 \%$ dos usuários perde[ram] seu abastecimento de água corrente na moradia e começou a depender de fontes públicas de água, poços, perfurações, rios, tanques e lagos” (Dagdeviren e Hailu, 2008, p.1)

${ }^{17}$ No Brasil "prevalece um pacto social, originário do país arcaico, expresso no ‘capitalismo politicamente orientado’, o capitalismo dos subsídios, das concessões, dos favores, das empreitadas, com as suas naturais sequelas, a corrupção, o clientelismo, às alianças interestatais com os burocratas (...)” (Faoro, 1988, p.33)

${ }^{18}$ No RDH de 2007/2008, capítulo 4, há uma longa discussão sobre adaptação aos riscos e ameaças climáticas. Tratam de diversos países (desenvolvidos e em desenvolvimento) e suas políticas de diminuição de riscos.

${ }^{19}$ A respeito da dupla hermenêutica, ver: (Melucci, 2005, Giddens, 1989, 1996). 


\section{Bibliografia}

Axworthy, L. (2004). “Human security: an opening for UN reform” Price, R. y Zacher, M. (Eds.), The United Nations and global security, New York, United States: Editora Palgraveele

Bauman, Z. (1999).Globalização: as consequências humanas. Rio de Janeiro, Brasil: Jorge Zahar Editora.

Idem, (2005). Vidas desperdiçadas. Rio de Janeiro, Brasil: Jorge Zahar Editora.

Idem, (2010). Hermenêutica e teoria social moderna. Em Ribeiro da Silva, F. Realismo e redes: dilemas metodológicos na obra de Anthony Giddens, (Tese de doutorado), São Paulo, Brasil: Universidade de São Paulo

Bourdieu, P. (2003).A miséria do mundo. Petrópolis, Brasil: Vozes

Castel, R. (1998).As metamorfoses da questão social: uma crônica do salário. Petrópolis, Brasil: Vozes

Cravo, T. (2009). O conceito de segurança humana: indícios de uma mudança paradigmática? En Nasser, R. (org.), Os conflitos internacionais em múltiplas dimensões, São Paulo, Brasil: Editora Unesp.

Dagdeviren, H. e Degol, H. (2008). Aumentos tarifarios con inversiones bajas: La historia del sector urbano del agua en Zambia.En One Pager (57). Recuperado de www.undp-povertycentre.org

Nações Unidas (1972). Declaration of the United Nations Conference on the Human Environment. Recuperado de http://www.unesp.org

Nações Unidas(1992). Declaração do Rio sobre Meio Ambiente e desenvolvimento. Recuperado de http://www.ONU.org.br/Rio20

Nações Unidas (2000). Declaração do Milênio. Assembleia Geral das Nações

Unidas. Recuperado de http://direitoshumanos.gddc.pt

Nações Unidas (2002). Declaração de Joanesburgo sobre Desenvolvimento Sustentável. Recuperado de http://mma.gov.br> Acesso em 28/10/14.

Dilthey, W. (1942).Introduction à l'Etude des Sciencies Humaines. Rio de Janeiro, Brasil: PUF Editor.

Idem (1988). Edification du monde historique dans les sciencies de l'Esprit.Paris, France: CERF Editora.

Elias, N. (1998).Envolvimento e alienação. Rio de Janeiro, Brasil: Bertrand Brasil Editora. 
Idem (1999), Introdução à Sociologia. Lisboa, Portugal: Edições 70.

Idem (2006). Tecnização e civilização. Em Escritos e Ensaios. Rio de Janeiro, Brasil: Jorge Zahar Editora.

Faria, V. (1992). A conjuntura social brasileira: dilemas e perspectivas. Em Novos Estudos -CEBRAP 0(33).

Flores-Galindo, M. (2009). Epistemología y hermenéutica: entre lo conmensurable y lo inconmensurable. En Cinta de Moebio Revista de Epistemología de Ciencias Sociales 0 (36). Recuperado de http:// www.cintademoebio.uchile.cl/index.php/CDM/article/view/18194/ 19069

Faoro, R. (1988). A constituinte em repouso. Istoé/Senhor 0 (982)

Furtado, C. (2001). O capitalismo global. Rio de Janeiro, Brasil: Editora Paz e Terra.

Idem (2002). Em busca de novo modelo. Rio de Janeiro, Brasil: Editora Paz e Terra.

Gadamer, H. (1998). Verdade e método: traços fundamentais de uma hermenêutica filosófica. Petrópolis, Brasil: Vozes Editores.

Giddens, A. (1989).A constituição da sociedade. São Paulo, Brasil: Martins Fontes Editores.

Idem (1996). Novas regras do método sociológico. Lisboa, Portugal: Gadiva Editora.

Gledhill, J. (2012), Segurança humana: uma meta viável?. Emaderno $C R H$, 25(66), 519-533. https://dx.doi.org/10.1590/S010349792012000300009

Judt, T. (2011).O mal ronda a terra. São Paulo, Brasil: Objetiva Editora.

Kaldor, M. (2007).Human Security: reflections on globalization and intervention. Cambridge, UK: Polity Press.

Levine, D. (1997).Visões da tradição sociológica. Rio de Janeiro, Brasil: Jorge Zahar Editora.

Melucci, A. (2005).Por uma Sociologia reflexiva. Petrópolis, Brasil: Vozes Editora.

Pureza, J. M. (2009). Segurança humana: vinho novo em odores velhos?. Em Nasser, R. (org.), Os conflitos internacionais em múltiplas dimensões. São Paulo, Brasil: Editora Unesp. 
PNUD/RDH (1994).Relatório do Desenvolvimento Humano 1994: Un programa para la cumbre mundial sobre desarrollo social. Recuperado de http://www.pnud.org/en/reports/global/hdr1994/download/ es

PNUD/RDH (1995). Relatório do Desenvolvimento Humano: La revolución hacia la igualdad en la condición de los sexos. Recuperado dehttp://hdr.undp.org/en/reports/global/hdr1995

PNUD/RDH (1996). Relatório do Desenvolvimento Humano: Crecimiento económico para propriar el desarrollo humano?Recuperado de http:/hdr.undp.org/en/reports/global/hdr1996

PNUD/RDH (1997). Relatório do Desenvolvimento Humano: desenvolvimento humano para erradicar a pobreza, PNUD/ONU, New York. Disponível em: http://hdr.undp.org/en/reports/global/ hdr1997

PNUD/RDH (1998).Relatório do Desenvolvimento Humano: Cambiar las pautas actuales de consumo para el desarrollo humano de futuro. Recuperado de http://hdr.undp.org/en/reports/global/hdr1998

PNUD/RDH (1999).Relatório do Desenvolvimento Humano: La mundialización com rostro humano. Recuperado de http:// hdr.undp.org/en/reports/global/hdr1999

PNUD/RDH (2000). Relatório do Desenvolvimento Humano 2000: Direitos Humanos e Desenvolvimento Humano. Recuperado de http:// www.pnud.org/en/reports/global/hdr2000/download/pt

PNUD/RDH (2001).Relatório de Desenvolvimento Humano 2001: Fazendo as novas tecnologias trabalhar para o desenvolvimento humano. Recuperado de http://www.pnud.org/en/reports/global/hdr2001/ download/pt

PNUD/RDH (2002). Relatório de Desenvolvimento Humano/2002: Aprofundar a democracia num mundo fragmentado. Recuperado de http://www.pnud.org/en/reports/global/hdr2002/download/pt

PNUD/RDH (2003). Relatório de Desenvolvimento Humano/2003: Um pacto entre nações para eliminar a pobreza humana. Recuperado dehttp://www.pnud.org/en/reports/global/hdr2003/download/pt

PNUD/RDH (2004).Relatório do Desenvolvimento Humano: A liberdade cultural no mundo diverso de hoje.Recuperado de http:// www.pnud.org.br

PNUD/RDH (2005). Cooperação internacional numa encruzilhada. Re- 
cuperado de http://www.pnud.org/en/reports/global/hdr2005/ download/pt

PNUD/RDH (2006). Além da escassez: poder, pobreza e a crise mundial da água.Recuperado de http://www.pnud.org/en/reports/global/ hdr2006/download/pt

PNUD/RDH (2007/2008).Relatório de Desenvolvimento Humano 2007/ 2008: Combater a mudança do clima - solidariedade frente a um mundo dividido.Recuperado de http://www.pnud.org/en/reports/global/hdr2001/download/pt

PNUD/RDH (2010). Relatório de Desenvolvimento Humano: A verdadeira riqueza das nações - caminhos para o desenvolvimento humano. Recuperado de http://www.pnud.org/en/reports/global/hdr2010/ download/pt

PNUD/RDH (2011).Relatório de Desenvolvimento Humano: Sustentabilidade e equidade - um futuro melhor para todos. Recuperado dehttp://www.pnud.org/en/reports/global/hdr2011/ download/pt

PNUD/RDH (2014).Relatório de Desenvolvimento Humano - sustentar o progresso humano - reduzir vulnerabilidades e construir resiliência. Recuperado de http://www.pnud.org.br/rdh

REPORTS of the S-G on Human Security (2010). Genebra, Secretaria Geral das Nações Unidas.Recuperado dehttp://www.unocha.org/ humansecurity-securitynow

REPORTS of the S-G on Human Security (2012). Genebra, Secretaria Geral das Nações Unidas. Recuperado de http://www.unocha.org/ humansecurity-securitynow

REPORTS of the S-G on Human Security (2013). Genebra. Secretaria Geral das Nações Unidas. Recuperado de http://www.unocha.org/ humansecurity-securitynow

Ricoeur, P. (1988). Interpretação e ideologias. Rio de Janeiro, Brasil: Francisco Alves.

Idem (2000).Teoria da interpretação. Lisboa, Portugal: Edições 70.

Rudiger, F. (2009).Ciência social crítica e pesquisa em comunicação: trajetória histórica e elementos de epistemologia, Porto Alegre, Brasil: Gattopardo.

Santibáñez, C. (2012), Teoria da argumentación como epistemologia aplicada. En Cinta de MoebioRevista de Epistemología de Ciencias Socia- 
les 0 (43). Recuperado de http://www.cintademoebio.uchile.cl/ index.php/CDM/article/view/25888/27204

Sen, A. (2006). El valor de La democracia. Madrid, España: El Viejo Topo.

Idem (2010).Desenvolvimento como liberdade. São Paulo, Brasil: Cia das Letras Editora.

Soares, L. E. (1988). Hermenêutica e Ciências Humanas. EmRevista Estudos históricos 1 (1), 100 - 142. Recuperado de http:// bibliotecadigital.fgv.br/ojs/index.php/reh/article/view/1932/1071

Souza Santos, B. (1989). Metodologia e hermenêutica I e II. En Introdução a uma Ciência pós-moderna.Lisboa, Portugal: Edições Afrontamento.

Suhrke, A. (1999). Human security and the interests of sates. En Security Dialogue 30 (3).

Therborn, G. (1999). Globalizations and modernities: European and Latin American Experiences and Perspectives, Stockholm, Sweden: FRN Editor.

Idem (2001). Globalização e desigualdades: questões de conceituação e esclarecimentos. Em Sociologias 0 (6), 122-169. Recuperado de http:/ /seer.ufrgs.br/index.php/sociologias/article/view/5768/3374

Idem (2010). Os campos de extermínio da desigualdade. Em Novos Estudos -CEBRAP 0(87), 145 - 156. Recuperado de http://novosestudos. uol.com.br/v1/files/uploads/contents/148/20100816_08_ Therborn_87_144a157.pdf

Thompson, J. (1995). Ideologia e cultura moderna, Petrópolis, Brasil: Vozes Editora.

Tilly, C. (1998). Durable inequality. Berkeley, United States: University of California Press.

Tralhão, R. (2009). O sujeito no pensamento social: a hermenêutica e as Ciências Sociais e Humanas. EnInteracções. Revista da Escola Superior de Educação de Santarém(16). Recuperado de www.interacoes.com/index.php

Veiga, J. E. (2011). Osso muito duro de roer. En Folha de S. Paulo, 01 jan. C1, p.3, São Paulo 